\title{
EFFECT OF SULFUR COMPOUNDS ON THE PROTEASE FORMATION BY ASPERGILLUS NIGER
}

\author{
GŌTARŌ TOMONAGA, HIROBUMI OHAMA and TOMOMICHI YANAGITA \\ Institute of Applied Microbiology, University \\ of Tokyo, Bunkyo-ku, Tokyo \\ Received November 17, 1964
}

An exoenzyme formation by fungi has been known to proceed actively in complex media but only poorly in synthetic media. During the course of our investigations on the growth and differentiation of fungi, it was confirmed that Aspergillus niger grown on a synthetic medium containing sulfate produced appreciably no protease irrespective of its active growth. By contrast, if the fungus was grown on the same medium devoid of added sulfate, it grew only poorly but produced a large amount of protease in the medium. This finding is of interest when referred to the earlier observations by several workers $(1,2,3)$ that the exoenzyme formation of bacteria was largely inhibited by the presence in media of sulfur compounds.

The present investigation was carried out to disclose physiologically the effect of sulfur compounds on the protease formation by Aspergillus niger. Stress was also laid on the comparison of the protease formations in the sulfur-deficient synthetic medium and that in a complex medium.

\section{MATERIALS AND METHODS}

Organisms and cultivation. Aspergillus niger strain 1617 was used throughout the experiments. For comparison, several other strains of aspergilli shown in Table 2 were also employed as test organisms. Culture media used for the cultivation of fungi were as follows. The synthetic medium contained per liter: sodium L-glutamate, $0.3 \mathrm{~g}$; DL-alanine, $0.3 \mathrm{~g}$; L-aspartic acid, $0.3 \mathrm{~g} ; \mathrm{NaNO}_{3}, 2.0 \mathrm{~g} ; \mathrm{KH}_{2} \mathrm{PO}_{4}, 1.0 \mathrm{~g} ; \mathrm{KCl}, 0.5 \mathrm{~g} ; \mathrm{MgSO}_{4} \cdot 7 \mathrm{H}_{2} \mathrm{O}$, $0.25 \mathrm{~g} ; \mathrm{FeCl}_{3} \cdot 6 \mathrm{H}_{2} \mathrm{O}, 0.01 \mathrm{~g}$; and glucose, $20 \mathrm{~g}$ ( $\mathrm{pH} 6.0$ ). When necessary, $\mathrm{MgSO}_{4} \cdot 7 \mathrm{H}_{2} \mathrm{O}$ was replaced by $\mathrm{MgCl}_{2} \cdot 6 \mathrm{H}_{2} \mathrm{O}$ and known amounts of $\mathrm{Na}_{2} \mathrm{SO}_{4}$ (or other sulfur compounds) were added to make the media of varied sulfur concentrations. The peptone medium contained per liter: Polypepton (Takeda Chemicals Co.), $3.0 \mathrm{~g} ; \mathrm{KH}_{2} \mathrm{PO}_{4}, 1.0 \mathrm{~g} ; \mathrm{KCl}, 0.5 \mathrm{~g} ; \mathrm{MgSO}_{4} \cdot 7 \mathrm{H}_{2} \mathrm{O}, 0.25$ $\mathrm{g} ; \mathrm{FeCl}_{3} \cdot 6 \mathrm{H}_{2} \mathrm{O}, 0.01 \mathrm{~g}$; and glucose, $20 \mathrm{~g}(\mathrm{pH} 6.0)$.

For the cultivation of the fungus, either surface or submerged culture was employed for comparison. For the surface culture, dry spores formed on the filterpaper culture (4) were spread as uniformly as possible (usually ca. $10^{4}$ spores per $\mathrm{cm}^{2}$ ) over a $100 \mathrm{ml}$ Elrenmeyer flask containing $30 \mathrm{ml}$ of the medium and incubated statically at $30^{\circ}$. The area of mycelial mat thus obtained was usually about $30 \mathrm{~cm}^{2}$. For a submerged culture, a spore 
suspension was inoculated into a Sakaguchi flask at the final concentration of $10^{2}$ spores per $\mathrm{ml}$ and cultured at $30^{\circ}$ on a rotary shaker $(180 \mathrm{rpm}$ at the working diameter of $10 \mathrm{~cm}$ ). Under the present conditions, the submerged cultivation of the fungus resulted in the formation of a large number of pellets.

Estimation of biosynthetic activity of fungal cells. The rate of ${ }^{35} \mathrm{~S}-$ incorporation into cellular protein was taken as a criterion of the biosynthetic activity of the fungal cells (5). In case of surface culture a mycelial mat was gently floated on a medium containing $5 \mu \mathrm{c}$ per $\mathrm{ml}$ of ${ }^{35} \mathrm{~S}-$ sulfate and incubated statically at $30^{\circ}$ for $2 \mathrm{hr}$, while in submerged culture the fungal pellets were suspended in a medium containing the same amount of ${ }^{35} \mathrm{~S}$ as above and incubated in a water bath at $30^{\circ}$ by shaking for $1 \mathrm{hr}$. Then, fungal cells of each run were collected and homogenized in a Waring blender followed by the treatment with a French pressure cell. To the disintegrated cell suspension was added 10\% trichloroacetic acid (TCA) at the final concentration of $10 \%$. After the centrifugation of the suspension, the precipitate was treated with $0.1 \mathrm{~N} \mathrm{NaOH}$ to solubilize major protein. After centrifugation of the alkaline suspension, the supernatant was neutralized with $0.1 \mathrm{~N} \mathrm{HCl}$, dried on a planchet and subjected to radioactivity measurement with an end-window or a gas flow counter. The biosynthetic activity of a sample was defined taking either radioactivity per $\mathrm{cm}^{2}$ of mycelial mat in the case of surface culture or radioactivity per $\mathrm{mg}$ dry weight of pellets in the case of submerged culture.

Analytical procedures. The protease activity was assayed by the method of HaGiwara ( 6 ) at $\mathrm{pH} 3.0$ using $0.5 \%$ casein as substrate, reaction temperature being at $30^{\circ}$. The activity unit was defined as [PU] ${ }_{\gamma}^{\text {Cas. Fr. }}$. A. according to the same author.

Protein content was measured mainly by the method of LowRy ( 7$)$, and in case of column chromatography by measuring the absorbancy at $280 \mathrm{~m} \mu$.

For the determination of sulfur content, a sample was digested with PIRIE's reagent (8) for $10 \mathrm{hr}$ at $250^{\circ}$ and the resulting digest was neutralized with $\mathrm{KOH}$, and then subjected to colorimetric determination of sulfate according to the method of LETONOFF et al. (9).

The dry weight of mycelia was measured after drying at $105^{\circ}$ for $2 \mathrm{hr}$.

Purification of protease. After filtering off the fungal mycelia, ammonium sulfate was added to the culture medium to $80 \%$ saturation and the mixture was kept over night at $5^{\circ}$. The precipitate was collected by filtration and dissolved in $0.01 \mathrm{~m}$ lactate buffer $(\mathrm{pH} 3.0)$. The solution was centrifuged at $10,000 \times g$ to make it clear, lyophilyzed to a small volume, and then subjected to dialysis against the lactate buffer. The enzyme solution was applied on a Sephadex G-25 column $(1.5 \times 30 \mathrm{~cm})$ and eluted with the same buffer. The protease fractions were combined, lyophilyzed and dialyzed against $0.01 \mathrm{~m}$ lactate buffer containing $0.05 \mathrm{M} \mathrm{NaCl}$. The enzyme solution thus obtained was then applied on a SE-Sephadex C-50 
column $(2 \times 15 \mathrm{~cm})$ equilibrated with the same lactate- $\mathrm{NaCl}$ solution and subjected to gradient elution with the following solvent system : $200 \mathrm{ml}$ of $0.01 \mathrm{~m}$ lactate buffer containing $0.05 \mathrm{M} \mathrm{NaCl}$ in the mixing flask and $200 \mathrm{ml}$ of the same buffer containing $0.5 \mathrm{M} \mathrm{NaCl}$ in the inlet flask. The flow rate was $0.2 \mathrm{ml}$ per min and fractions of 6.0 to $6.3 \mathrm{ml}$ were collected. The protease fractions were combined and stored at $-20^{\circ}$.

\section{RESULTS}

Effect of various sulfur compounds on protease formation

When the fungus was grown statically on the synthetic medium, it grew normally and conidia formation occurred after 2.5-3 days of cultivation, but the protease was formed in the medium only slightly during the course of culture. On the other hand, when sulfate was completely omitted from the same medium, the growth of this fungus was very poor showing no development of aerial hyphae and no formation of conidia. It was, however, noticed that remarkable protease formation was demonstrated under the condition indicated in Fig. 1. The protease thus formed had the $\mathrm{pH}$ optimum at around $\mathrm{pH} 3$. The fact that the cell-free extract of mycelia grown on sulfur-deficient synthetic medium did not exhibit any appreciable activity of protease clearly indicates that the protease liberated in the medium is not an endoenzyme but a typical exoenzyme.

In Table 1 are shown the results of experiments on the

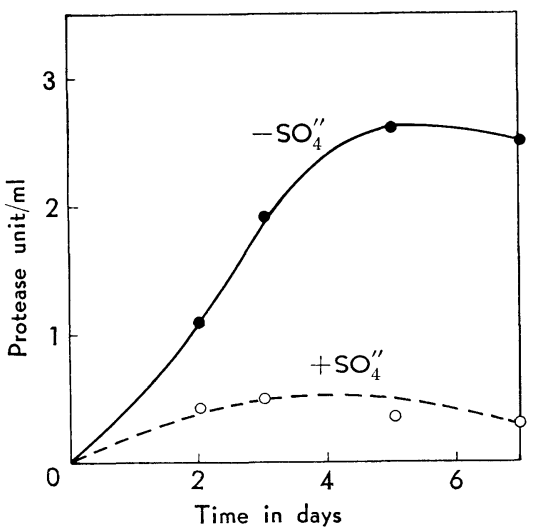

Fig. 1. Effect of sulfate $\left(10^{-3} \mathbf{M}\right)$ on protease formation by Aspergillus niger.

Surface culture on synthetic medium.

effect of various sulfur compounds on the protease formation and on the growth of the fungus. It is clear that the protease formation was much lower (or even nil) in the presence than in the absence of these compounds, even though the growth was much improved accompanied with conidiation in their presence. In the following experiments sodium sulfate was used throughout as the effector. It is worth mentioning also that such effect of sulfate on the protease formation was widely observed among other aspergilli (Table 2).

\section{Effect of sulfate concentration on protease formation}

To clarify the effect of sulfate quantitatively, the fungus was cultured statically on the synthetic media containing various concentrations of 
Table 1. Effect of various sulfur compounds on protease formation of Aspergillus niger (5 days culture).

\begin{tabular}{l|c|c|c}
\hline Compound $\left(10^{-3} \mathrm{M}\right)$ & Protease U/ml & Growth & Conidia formation \\
\hline $\mathrm{Na}_{2} \mathrm{SO}_{4}{ }^{a}$ & 0.8 & H & + \\
$\mathrm{Na}_{2} \mathrm{~S}_{2} \mathrm{O}_{3}$ & 0.9 & H & + \\
$\mathrm{Na}_{2} \mathrm{SO}_{3}$ & 0.5 & H & + \\
L-Cystine & 0 & H & + \\
L-Cysteine & 0 & H & + \\
L-Methionine & 0 & H & + \\
DL-Ethionine & 0.3 & + & - \\
Biotin & 1.0 & + & - \\
Thiamine & 0.4 & + & - \\
\hline
\end{tabular}

$a$ Under the present experimental conditions, the fungus produced 8.9 unit per $\mathrm{ml}$ of protease in the presence of a limited amount $\left(3 \times 10^{-5} \mathrm{M}\right)$ of $\mathrm{Na}_{2} \mathrm{SO}_{4}$.

Table 2. Effect of sulfate concentration on protease formation of various strains of Aspergillus (5 days culture).

\begin{tabular}{l|c|c}
\hline \multirow{2}{*}{ Strain } & \multicolumn{2}{|c}{ Protease formed in presence of $\mathrm{Na}_{2} \mathrm{SO}_{4}$} \\
\cline { 2 - 3 } & $10^{-3} \mathrm{M}$ & $3 \times 10^{-5} \mathrm{M}$ \\
\hline & $\mathrm{U} / \mathrm{ml}$ & $\mathrm{U} / \mathrm{ml}$ \\
A. aureus IAM 2090 & 1.3 & 4.4 \\
A. batatae IAM 2098 & 0.4 & 5.3 \\
A. carbonarius IAM 2099 & 0.1 & 4.6 \\
A. usamii IAM 2186 & 0.1 & 3.8 \\
A. saitoi IAM 2196 & 0.2 & 4.9 \\
A. inuii IAM 2257 & 7.8 & 11.6 \\
A. aureus IAM 2275 & 0.1 & 2.2 \\
A. awamori IAM 2334 & 1.4 & 2.5 \\
A. sojae IAM 2666 & 0 & 0.2 \\
\hline a days
\end{tabular}

a 3 days culture

sulfate and the dry weights of mycelial mats and protease activities in the media were determined. As seen in Fig. 2, the optimum concentration of sulfate for the protease formation was $3 \times 10^{-5} \mathrm{M}$, while the growth was improved as the concentration increased upto $10^{-3} \mathrm{M}$.

Morphological observations of mycelial mats grown under such conditions disclosed that conidiation was almost entirely inhibited in the absence or presence of less than $3 \times 10^{-5} \mathrm{M}$ sulfate, whereas it occurred in the presence of more than $10^{-4} \mathrm{M}$ sulfate. It seems apparent from these results together with those shown in Table 1 that the fungus is capable of protease formation in the synthetic medium under a limited cultural condition leading 


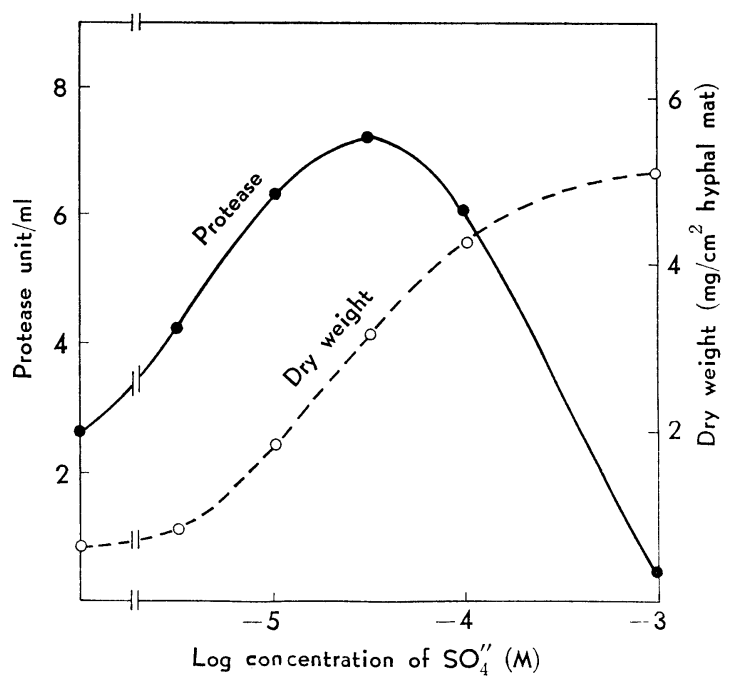

Fig. 2. Protease formation and dry weight of cells as a function of sulfate concentration.

Protease activity and dry weight were estimated after 5 days of culture.

to the inhibition of conidiation. To check the validity of this consideration, another cultural condition which caused the inhibition of conidiation was employed for the examination of the enzyme formation. When phosphate was omitted from the synthetic medium leaving sulfate unremoved, the fungus grew on it only poorly without forming aerial hyphae and conidia just like as when it grew on the sulfate-deficient medium. However, no protease was formed in this phosphate-deficient medium. It is, therefore, unlikely to correlate the protease formation of the fungus with the inhibition of conidiation.

In the above experiments demonstrating the effect of concentration of sulfate on protease formation, the fungus was grown statically on the media and observations were made after 5 days of cultivation. In the following experiments, the fungus was cultured by shaking in the media containing various concentrations of sulfate to see if the sulfur-concentration dependency of the protease formation in the submerged culture may be similar to that observed in the surface culture and if the concentration dependency may change during the course of cultural development. In Fig. 3 are presented the concentration dependency curves observed at various times indicated in the figure during the course of cultivation. The broken line plotting the optimum values obtained at each time interval represents the time course of protease formation under the optimum condition. These results clearly indicate that the optimum sulfate-concentration for the protease formation in submerged culture was almost constant at around $10^{-4} \mathrm{M}$ during the cultivation, showing the similarity of the value to that observed in the surface culture. 


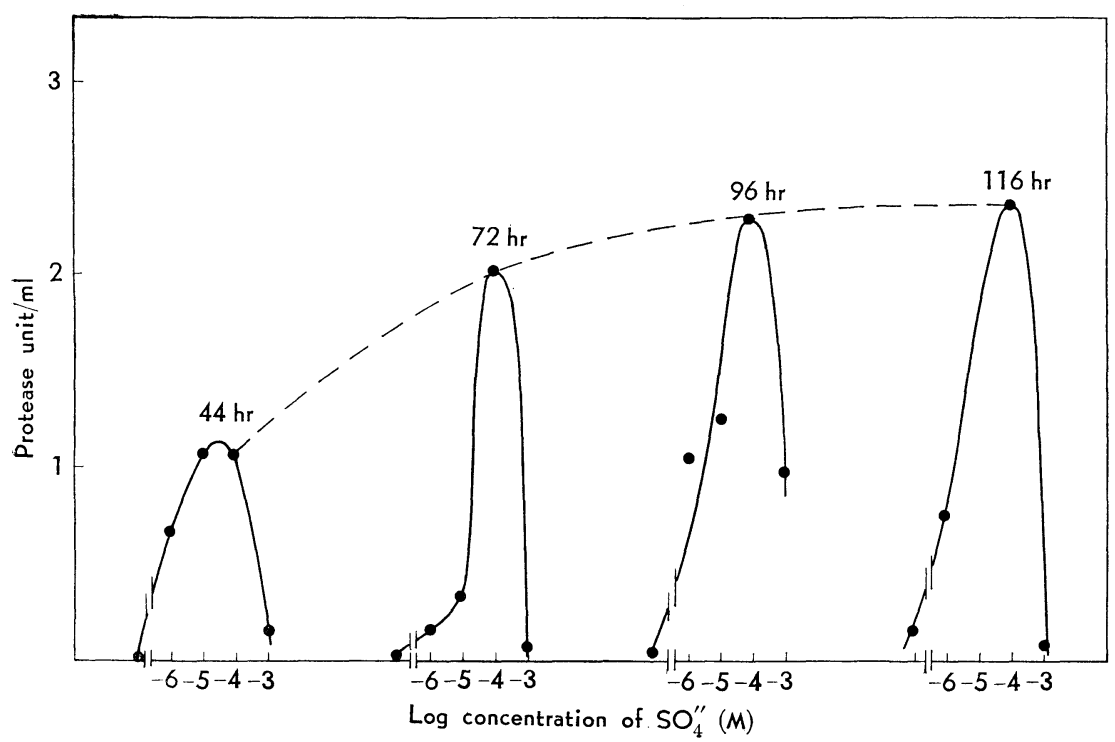

Fig. 3. Sulfate concentration dependencies of protease formation during the course of submerged culture of Aspergillus niger in a synthetic medium.

Time indicated represents sampling time. Broken line represents change in protease activity during cultivation at sulfate concentration of $10^{-4} \mathrm{M}$.
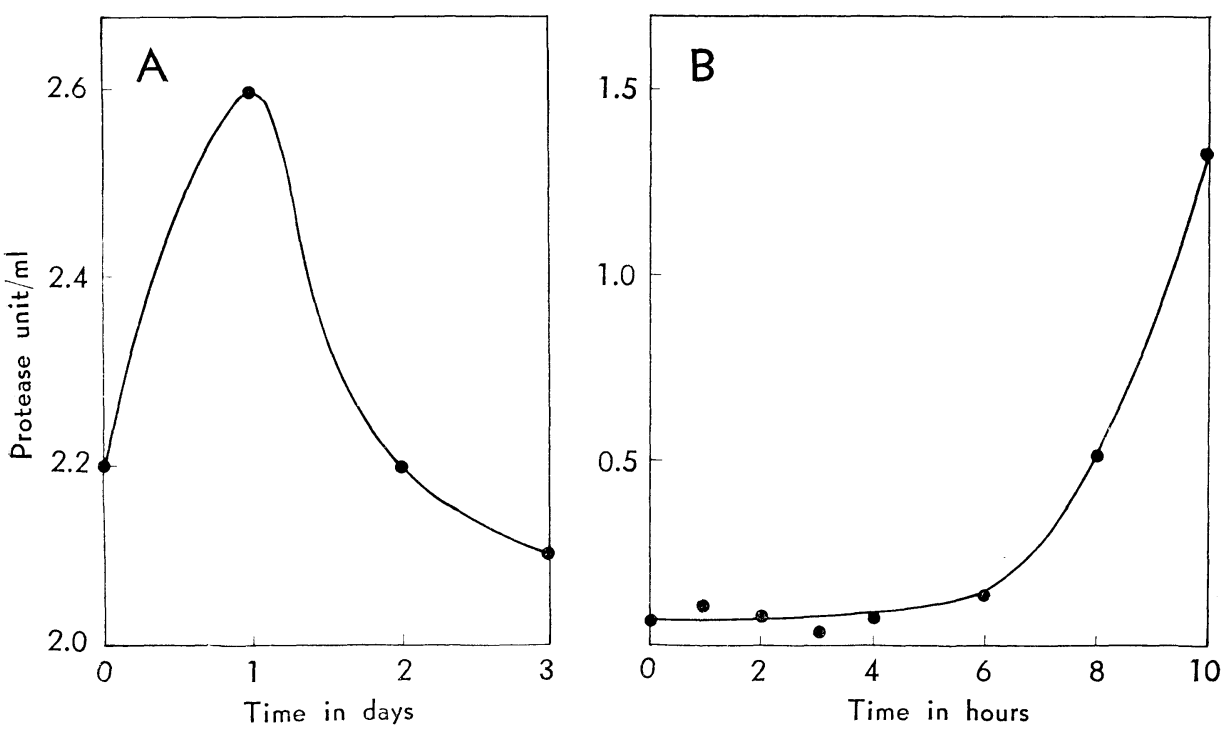

Fig. 4. Course of protease formation by Aspergillus niger after the transfer of hyphal mat onto media containing different concentration of sulfate.

A, from sulfate-deficient medium to sulfate-rich medium $\left(10^{-3} \mathbf{M}\right) ; B$, from sulfaterich medium $\left(10^{-3} \mathrm{M}\right)$ to sulfate-deficient medium. Time zero represents time of transfer. 
Effect of change in cultural condition with respect to sulfate concentration

When the fungus was initially grown statically on the sulfate-deficient synthetic medium, an appreciable amount of protease was formed as already shown in Fig. 1. After 3 days of this culture, in which active formation of the enzyme had continued, sulfate was added to it at the final concentration of $10^{-3} \mathrm{M}$ and the protease activity in the culture was further followed. As seen in Fig. 4-A, protease was continued to be formed for one more day in the culture even in the presence of excess sulfate and the course of inactivation of the enzyme followed.

By contrast, when the fungus was grown initially on the sulfatesufficient $\left(10^{-3} \mathrm{M}\right)$ synthetic medium for one day and then transferred to the sulfate-deficient medium after thorough washing of the mycelial mat by repeated floatations on sterilized water, the protease activity in the latter medium increased taking a course shown in Fig. 4-B. After $6 \mathrm{hr}$ of lag period, the protease activity began to increase and its formation continued for about 1 day at a constant rate of $0.4 \mathrm{U} / \mathrm{ml} \cdot \mathrm{hr}$.

Comparison of physiological states of mycelia producing protease in synthetic and complex media

In the preceding experiments, the physiological state of mycelia which had been grown in the S-rich medium was considered to affect the capacity to produce protease after being stepped down onto the S-deficient medium. To examine such possibility, the relationship between the biosynthetic activity of mycelia at the time of the step-down and the rate of protease formation in the S-deficient medium was investigated.

A circular mycelial mat $\left(c a .30 \mathrm{~cm}^{2}\right)$ grown statically on the S-rich medium taken at intervals was cut into two halves with a sterilized scissors, then the one was subjected to ${ }^{35} \mathrm{~S}$-incorporation experiment by the method described in Materials and Methods and the other was transferred onto the S-deficient medium for the measurement of protease forming ability (protease formed per day).

In general the biosynthetic activity as expressed by the ${ }^{35} \mathrm{~S}$-incorporation rate per unit area of the mycelial mat was very high at early stages of growth (up to 1 day) and the activity decreased gradually during the following 2 days ; at the end of this experiment on $3 \mathrm{rd}$ day, the said activity was only less than $5 \%$ of that of 1 st day mycelia. The rate of protease formation after the step-down was also high at early stages of the preceding culture in the S-rich medium and then it decreased gradually; after 3 days the rate was about $25 \%$ of that of 1 day culture. In Fig. 5-A are plotted data representing the relationship between the biosynthetic activity of the preceding culture and the rate of protease formation in the step-down culture. It was thus demonstrated that the protease was formed at high rates when actively growing mycelia characterized by the high biosynthetic activities were stepped down onto the S-deficient medium. 

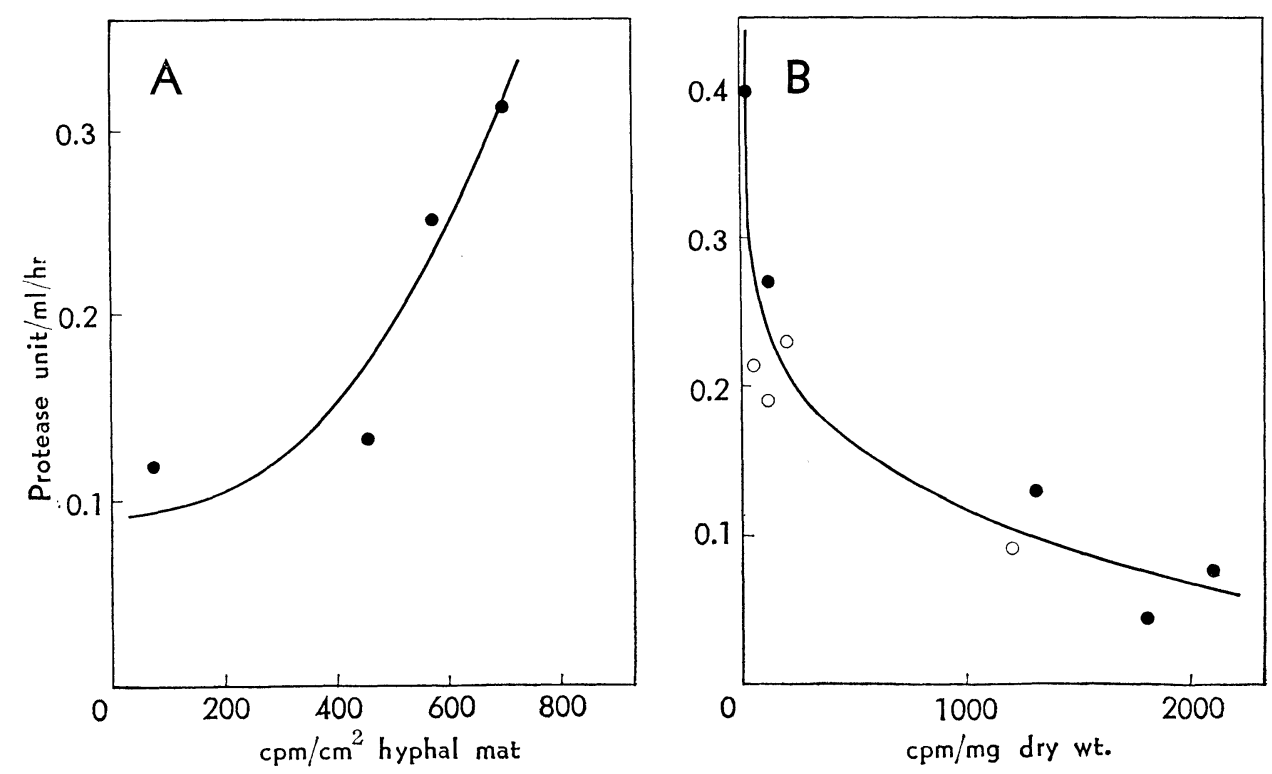

Fig. 5. Relationship between biosynthetic activity and protease forming capacity of Aspergillus niger hyphae.

For method of experiment see text.

A, cultured on synthetic medium; B, cultured in complex medium.

Such results were rather unexpected, since it has been known that the exoenzyme formation by microorganisms, in general, ensues after the active growth phase has passed (10). Therefore, the following experiments were carried out to compare the above relationship with that existing in the submerged culture in a complex medium.

The fungus was cultured by shaking in the peptone medium and samples were taken at intervals, filtered and the ${ }^{35} \mathrm{~S}$-incorporation activity of the mycelia was measured as described previously. In parallel with this measurement, the protease activity in the medium was followed during the course of culture and the rate of protease formation (tangent to the protease activity curve) at each sampling time was determined. In this culture, as usually the case, the active protease formation occurred when the biosynthetic activity of the mycelia became highly reduced. The relationship between the biosynthetic activity and the capacity to produce protease are shown in Fig. 5-B. Thus, in the peptone medium quite a reverse relationship to that observed in the step-down experiment (in the synthetic medium) was observed.

In the peptone medium there is one possible explanation for the late formation of protease that excess sulfur compounds contained in the medium retards the enzyme formation in the earlier phases of growth and after the exhaustion of these substances at later phases the protease is begun 
to be formed. The sulfur content in the peptone medium was as high as $7 \times 10^{-4} \mathrm{M}$ (as sulfate) even at the end of cultivation, the finding which excludes the above possibility.

Comparison of proteases produced in synthetic and peptone media

To compare the chemical characteristics of proteases produced in the S-deficient synthetic and peptone media, the enzymes were purified by ammonium sulfate precipitation and successive chromatographies employing Sephadex G-25 and SE-Sephadex C-50 columns as described previously. The process of purification is indicated in Table 3.

Table 3. Purification procedure of Aspergillus niger proteases.

\begin{tabular}{|c|c|c|c|c|}
\hline \multirow[b]{2}{*}{ Procedure } & \multirow[b]{2}{*}{$\begin{array}{l}\text { Volume } \\
(\mathrm{ml})\end{array}$} & \multicolumn{2}{|c|}{ Protease } & \multirow{2}{*}{$\begin{array}{l}\text { Specific } \\
\text { activity } \\
\text { (U/mg } \\
\text { prot.) }\end{array}$} \\
\hline & & $\begin{array}{l}\text { Sample } \\
\text { activity } \\
(\mathrm{U} / \mathrm{ml})\end{array}$ & $\begin{array}{l}\text { Total } \\
\text { activity } \\
\text { (U) }\end{array}$ & \\
\hline Culture filtrate & 2,900 & 7.2 & 20,880 & 30.1 \\
\hline $\begin{array}{l}\text { fractionated } \\
\text { with }\left(\mathrm{NH}_{4}\right)_{2} \mathrm{SO}_{4} \\
(0.8 \text { saturation })\end{array}$ & & & & \\
\hline \multicolumn{5}{|l|}{ Precipitates } \\
\hline $\begin{array}{l}\text { dissolved in } 0.01 \mathrm{M} \\
\text { lactate buffer (pH } 3.0) \\
\text { and centrifuged }\end{array}$ & & & & \\
\hline Supernatant & 60 & 310 & 18,600 & 111.5 \\
\hline \multicolumn{5}{|l|}{$\begin{array}{l}\text { desalted with Sephadex } \\
\text { G-25 column }\end{array}$} \\
\hline Effluent & 90 & 116 & 10,440 & 123.5 \\
\hline \multicolumn{5}{|l|}{$\begin{array}{l}\text { lyophilyzed } \\
\text { and dialyzed }\end{array}$} \\
\hline \multicolumn{5}{|l|}{ Solution } \\
\hline \multicolumn{5}{|l|}{$\begin{array}{l}\text { charged on } \\
\text { SE-Sephadex } \\
\text { column and eluted } \\
\text { by gradient } \mathrm{NaCl}\end{array}$} \\
\hline \multicolumn{5}{|l|}{ Enzyme preparation } \\
\hline peak (fast) & 42 & 82 & 3,444 & 89.9 \\
\hline peak (slow) & 30 & 93 & 2,790 & 531 \\
\hline
\end{tabular}

As clearly seen from Fig. 6-A, representing the elution pattern of the SE-Sephadex C-50 chromatography, the protease produced after the step-down of mycelia from the S-rich to S-deficient media was composed chromatographically of two components. The fast eluted peak was somewhat bigger than the slow one and the specific activity (protease unit per $\mathrm{mg}$ protein) of the latter was usually much higher than that of the former: this is clearly shown in Table 3. Such finding seems to be in accordance with that of KoAzE (11) who also employed Aspergillus niger. The pH-activity 


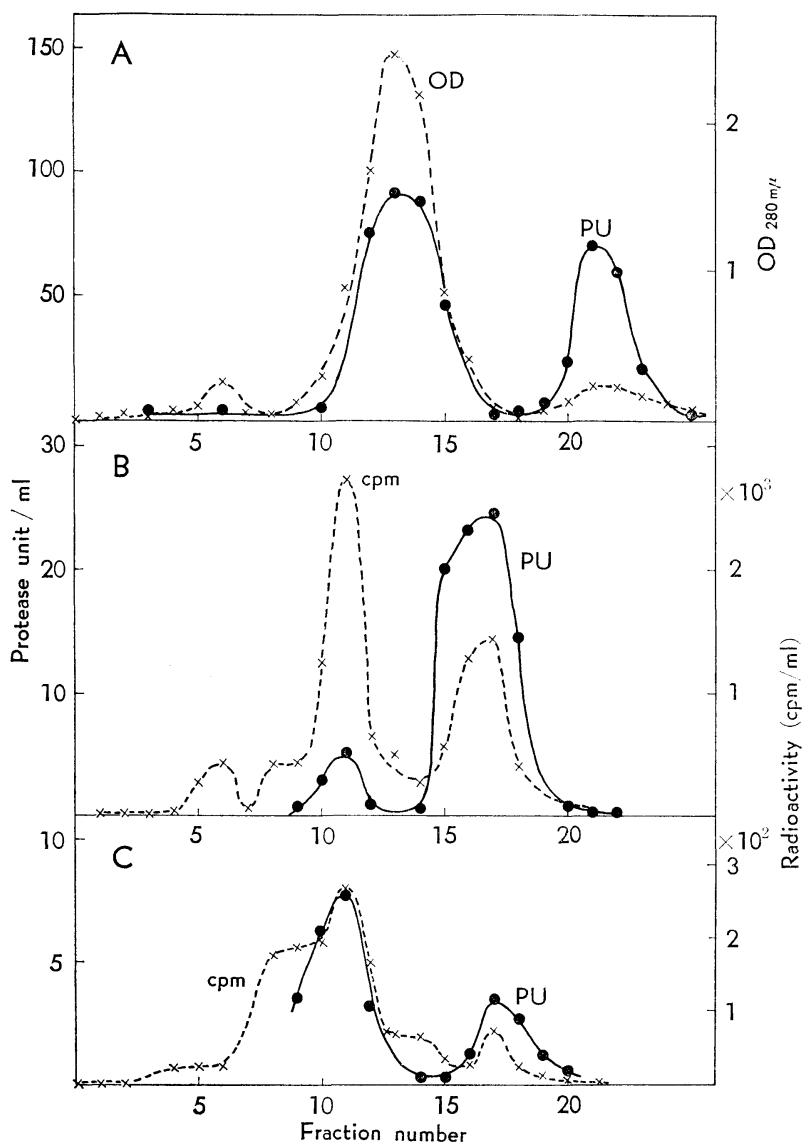

Fig. 6. SE-Sephadex C-50 column chromatography of proteases produced by Aspergillus niger.

A, proteases produced in sulfur-deficient medium; B, proteases produced in complex medium containing ${ }^{14} \mathrm{C}$-amino acid mixture $(0.15 \mathrm{mc} / \mathrm{liter})$; and $\mathrm{C}$, combined sample of protease preparations of $\mathrm{A}$ and $\mathrm{B}$.

curves and the thermostability curves are shown in Fig. 7 and 8, respectively. The $\mathrm{pH}$ optimum of fast eluted protease was more acidic ( $\mathrm{pH} 1.5)$ than that of the slowly eluted one ( $\mathrm{pH} 3.0$ ), and the former showed higher thermostability than the latter. These characteristics were also similar to the proteases isolated by KOAZE (11). Similar biphasic elution pattern was also obtained for the protease sample which had been produced by the fungus cultured throughout on the S-limited (containing $3 \times 10^{-5} \mathrm{M}$ sulfate) synthetic medium.

To compare the elution pattern of the protease produced in the synthetic medium with that in the peptone medium, the latter enzyme was labelled 


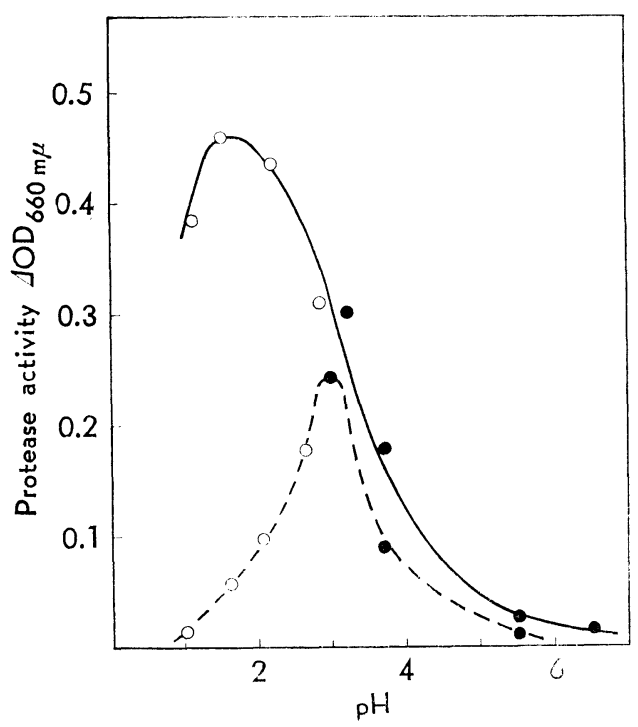

Fig. 7

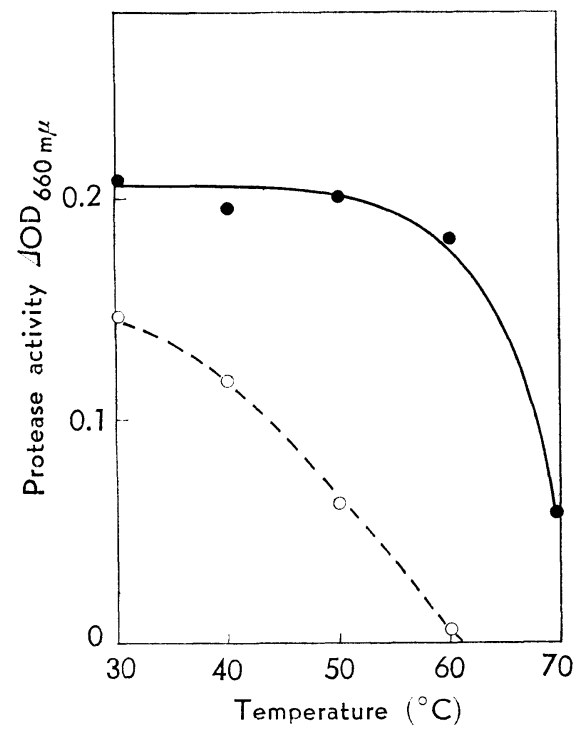

Fig. 8

Fig. 7. pH-activity curves of proteases produced by Aspergillus niger.

Solid and broken lines represent fast and slowly eluted proteases, respectively.

Open and closed circles represent Walpole's (12) and Mcllvaine's (13) buffers, respectively, used for estimation of enzyme assay.

Fig. 8. Thermostability curves of proteases produced by Aspergillus niger.

- - fast eluted protease.

-. - - : slowly eluted protease.

Proteases dissolved in $0.2 \mathrm{M}$ lactate buffer were heated for $15 \mathrm{~min}$ at varied temperatures.

with ${ }^{14} \mathrm{C}$-amino acid. The fungus was cultured for 3 days by shaking in the peptone medium containing $0.15 \mathrm{mc} /$ liter of ${ }^{14} \mathrm{C}$-amino acid mixture prepared from labelled Chlorella cells (obtained by courtesy of Prof. B. Maruo of this Institute). After the purification by the same procedure as described above, the SE-Sephadex elution pattern of the enzyme preparation thus labelled (Fig. 6-B) was compared with that presented in Fig. 6-A. In this case also the presence of two chromatographically different forms of proteases were demonstrated and the slow eluted peak was much bigger than the fast one, indicating the two proteases were produced at quite different ratios when the fungus was cultured under different conditions.

To ascertain the identity of the respective proteases produced under the different conditions, the unlabelled purified protease preparation formed by the step-down technique and the labelled one formed in the peptone medium were mixed and chromatographed with a SE-Sephadex column. As seen from the elution patterns shown in Fig. 6-C, either two peaks of both enzyme preparations seemed to coincide with each other. 


\section{DISCUSSION}

It has long been experienced that the exoenzyme formation in fungi occurs actively in complex media but only poorly or even nil in synthetic media. The present investigation throws a light on the elucidation of this problem.

As already pointed out by several workers, exoenzyme formations by bacteria were inhibited by some sulfur compounds added to the fermentation media (1, 2, 3). The present experiment also showed that the formation of protease by Aspergillus niger was retarded in the presence in a synthetic medium of a certain amount of sulfur compound which can support abundant growth of the. fungus, whereas the protease formation proceeded actively irrespective of the poor growth in the absence or in the presence of a minute amount of the compound. In the case of sulfate, the optimum concentration for the protease formation was found to be $3 \times 10^{-5} \mathrm{M}$; this was about one thirtieth of the physiological concentration of sulfate $\left(10^{-3}\right.$ m) at which normal growth of the fungus can proceed. This optimum value seemed to be independent of cultural forms (surface vs. submerged cultures) and culture ages, and this phenomenon was found to be generally observed in other aspergilli.

Among sulfur compounds so far tested, the salts of inorganic sulfuroxy acids and sulfur amino acids which could support active growth of the fungus were found to be effective in supressing protease formation. This suggests that the mechanism being involved in this phenomenon is related to the sulfur content of the protease protein to be synthesized.

Pollock (14) reviewed the chemical characteristics of exoenzymes produced by bacteria. He pointed out that exoenzymes in general are characterized by a low content of sulfur amino acids. Although no datum concerning the amino acid composition of the fungal exoenzyme is as yet available, the present observation that the protease in question was formed actively in a synthetic medium containing only a minute amount of sulfate seems to afford an indirect evidence suggesting the low content of sulfur amino acids in this protease. It should be noticed, however, that the situation is not so simple as to be able to conclude as such, since the chromatographically similar enzyme could be produced if the fungus was grown in a complex medium containing enough amount of sulfur compounds. Therefore, it awaits direct amino acid analysis using a highly purified enzyme preparation to deduce a final conclusion with respect to this problem.

When the hyphal mat grown on sulfate rich medium was stepped down to the sulfate-deficient medium, the protease was produced after a lag of $6 \mathrm{hr}$. In this experiment the age of the hyphal mat to be stepped down was found to be related to the rate of protease formation after the transfer. The younger was the hyphal mat, the higher was the rate of protease formation after the step-down; in other words, the higher was the 
biosynthetic activity of the hyphae, the higher was the rate of protease formation. By contrast, in a complex medium which support an active protease formation, the lower was the biosynthetic activity of the hyphae, the higher was the rate of protease formation.

Even though such a great variance in the physiological natures of the hyphae in the protease formation was demonstrated between the two cultures, it is of great interest to note that chromatographically similar, but not equal quantitatively, proteases were formed in both cases. Two proteases so far detected by the chromatography showed different $\mathrm{pH}$ optima and different thermostabilities as already demonstrated by Koaze (11).

Our recent investigation showed that during the course of submerged culture of this fungus, the fast eluted protease was produced only temporarily at the earlier phase of growth than when the slowly eluted protease was produced(15). In this communication we suggested that the former enzyme could be produced from the biosynthetically active hyphae and the latter from the less active ones. Indeed, the proteases produced actively from the biosynthetically active hyphae after the step-down to the sulfatedeficient medium was composed chromatographically of a large proportion of the fast eluted protease, whereas those produced actively from older hyphae grown in a complex medium was composed mainly of the slowly eluted protease. Therefore, it is highly probable that the variance in the physiological characteristics of the hyphae in producing proteases under different cultural conditions may reflect to the chemical natures of the proteases being formed.

\section{SUMMARY}

Aspergillus niger grown on a synthetic medium containing sulfate as source of sulfur produced appreciably no protease, but if the sulfate was limmited in the medium, it produced protease actively irrespective of its poor growth. The optimum concentration of sulfate for the protease formation was $3 \times 10^{-4} \mathrm{M}$, whereas sulfate concentration supporting heavy growth of the fungus was $10^{-3} \mathrm{M}$. By contrast, if the fungus was cultured in a complex medium containing peptone, the fungus produced protease actively irrespective of the high content of sulfur compounds.

The formations of proteases in the sulfur-deficient synthetic medium and in the complex medium seemed to depend on different physiological activities of the hyphae, but these enzymes produced in the two media showed similar chromatographic pattern, i.e., at least two proteases were produced in both cases, although the relative amount of these proteases were different in both cases. The mode of formation of these different proteases by growing hyphae was discussed. 


\section{REFERENCES}

(1) K. Morihara: Bull. Agr. Chem. Soc. (Japan), 23, 49 (1959).

(2) D. Tsuru: Agr. Biol. Chem., 26, 288 (1962).

(3) M. Oishi, S. Kitayama, H. Takahashi and B. Maruo: J. Gen. Appl. Microbiol., 9, 337 (1963).

(4) T. Yanagita and S. Yamagishi: Appl. Microbiol., 6, 375 (1958).

(5) T. Yanagita and F. Kogané: J. Gen. Appl. Microbiol., 9, 173, 331 (1963).

( 6 ) B. Hagiwara: Kōso Kenkyuho (Method of Enzymology) Vol. 2, 237, ed. by S. AKaboRI, Asakura Pub. Co., Tokyo (1956).

(7) O. H. Lowry, N. J. Rosebrough, A. L. FarR and R. J. Randall: J. Biol. Chem., 193, 265 (1951).

(8) J. LANGe and T. TARVer: Methods in Enzymology, Vol. 3, 995, ed. by S.P. Colowick and N. O. Kaplan, Academic Press, New York (1957).

( 9 ) T. V. Letonoff and J. G. Reinhold: J. Biol. Chem., 114, 147 (1936).

(10) M. R. Pollock: The Bacteria, Vol. 4, 121, ed. by I. C. Gunsalus and R. Y. Stanier, Academic Press, New York (1962).

(11) Y. Koaze, H. Goi, K. Ezawa, Y. Yamada and T. Hara: Agr. Biol. Chem., 28, 216 (1964).

(12) G. S. Walpole: J. Chem. Soc., 105, 2501 (1914).

(13) T. C. McIlvaine: J. Biol. Chem., 49, 183 (1921).

(14) M. R. Pollock and M. H. Richmond: Nature, 194, 446 (1962).

(15) H. Ohama, G. Tomonaga and T. Yanagita: J. Jap. Biochem. Soc., 36, 689 (1964) (abstract in Japanese). 